\title{
Estrategias de investigación para el tratamiento de Alzheimer con antioxidantes polifenólicos
}

\author{
Ligia Sierra \\ Grupo de Investigación Ciencia de los Materiales, Instituto de Química, Facultad de Ciencias Exactas y Naturales, \\ Universidad de Antioquia, Medellín, Colombia
}

Artículo de posesión para el ingreso como miembro correspondiente a la

Academia Colombiana de Ciencias Exactas, Físicas y Naturales el 6 de abril de 2016

\section{Resumen}

Esta revisión comprende una descripción de los mecanismos propuestos para explicar el desarrollo de la enfermedad de Alzheimer (EA) y de las estrategias para su tratamiento a la luz de estos mecanismos, enfatizando la utilización de compuestos polifenólicos como agentes terapéuticos. Se analizan los efectos de especies reactivas de oxígeno ROS y presencia de metales redox en el desarrollo de EA y las estrategias de tratamiento, basadas en la actividad antioxidante y quelante de un medicamento y en sus alcances a través de vías de señalización. Dada la importancia de los polifenoles tipo flavonoides para el tratamiento de EA, se tienen en cuenta ejemplos con el flavonoide (-)-epigalocatequin-3-galato (EGCG), perteneciente a la familia de las catequinas. Es importante estudiar como intervienen los polifenoles a nivel celular (rol de su estructura química en la interacción con la célula y en su actividad biológica) con el fin de modular la interacción y las vías de señalización para lograr los efectos neurotróficos esperados. Los efectos in vitro, frecuentemente no corresponden a aquellos in vivo, dado que diferencias en concentraciones y condiciones de estudio hacen que las actividades química y biológica de un medicamento varíen. Esto puede ser debido en parte a la necesidad de un ajuste en concentraciones y tiempo entre los estudios pre clínicos y clínicos. Por otra parte, métodos de liberación eficientes deben ser investigados, teniendo en cuenta que un agente terapéutico para enfermedades neurológicas debería cruzar la barrera sanguínea-cerebral. La nanotecnología basada en sistemas de liberación controlada de medicamentos puede superar estas limitaciones. (C) 2016. Acad. Colomb. Cienc. Ex. Fis. Nat.

Palabras clave: Enfermedad de Alzheimer; Placas amiloide; Marañas tau; Compuestos polifenólicos; Vías de señalización; Liberación controlada de medicamentos.

Research strategies for the treatment of Alzheimer desease with antioxidant polyphenolic compounds.

\begin{abstract}
This review includes a description of the proposed mechanisms to explain the development of Alzheimer's disease (AD) and strategies for treatment in the light of these mechanisms, with emphasis on the use of polyphenolic compounds as therapeutic agents. The effects of reactive oxygen species ROS and presence of metal redox in the development of AD and treatment strategies with a drug or active substance, based on antioxidant and chelating activity and in its potentiality through signaling pathways are analyzed. Given the importance of polyphenolic compounds as natural antioxidants for treating of $\mathrm{AD}$, in special the flavonoids family, this review takes into account examples of this family, with emphasis on the catechin type flavonoid (-)-epigalocatechin-3-gallate (EGCG). Understanding of how polyphenols are involved at the cellular level (role of its chemical structure in the interaction with the cell and therefore its biological activity) is required in order to modulate the interaction and signaling pathways to achieve the desired neurotrophic effects. Effects in vitro often do not correspond to those in vivo. Differences in concentrations and study conditions make that chemical and biological activities of a drug vary. This may be due in part to the need for an adjustment in concentration and time between preclinical and clinical studies. Furthermore, efficient release methods should be investigated, particularly considering that a therapeutic agent for neurological diseases should cross the blood - brain - barrier (BBB). Nano- technology based on controlled release systems of drugs may overcome these limitations. (C) 2016. Acad. Colomb. Cienc. Ex. Fis. Nat.
\end{abstract}

Key words: Alzheimer's disease; Amyloid-beta plaques; Tau tangles; Polyphenolic compounds; Signaling pathways; Controlled drug release.

Correspondencia: Ligia Sierra, ligia.sierra@gmail.com, Recibido: 30 de agosto de 2016, Aceptado: 21 de octubre de 2016 


\section{Introducción}

La enfermedad de Alzheimer (EA) es la causa de demencia más común entre la población mayor. En el 2011 se estimaba que en el 2020 la cifra de personas, en el mundo, con esta enfermedad aumentaría a 42 millones (Ballard, et al., 2011). Ya en el 2015 las estadísticas señalan que cerca de 44 millones de personas padecen de EA o una demencia relacionada (Alzheimers.net). Estas cifras alarmantes, justifican los esfuerzos que a nivel científico se vienen realizando para encontrar sus posibles tratamientos. Entender las bases moleculares que envuelven este desorden neurodegenerativo multifactorial sigue siendo un reto significativo (Castellani, Zhu, Lee, Smith y Perry, 2009).

EA está caracterizada por formaciones anómalas de proteínas, déficits colinérgicos, pérdida sináptica, inflamación, extenso estrés oxidativo (EO), presencia o ausencia de mutaciones en la línea de genes, presencia o ausencia de susceptibilidad morfológica en los alelos, entre otros. Estos cambios patológicos están acompañados por trastornos motrices y cognitivos que llevan a una mortalidad acelerada.

Las formaciones anómalas de proteínas son la base de EA de acuerdo a la hipótesis inicial de "cascada amiloide" con sus ampliaciones que incluyen aumento en EO y las hipótesis de tipo genético, epigenético y viral (Castellani, et al., 2009; Rossor, 1993). Recientemente las trayectorias de señalización celular han sido implicadas en la patología EA así como también procesos inflamatorios (Karunaweera, Raju, Gyengesi y Münch, 2015).

\section{Hipotesis de cascada amiloide}

Los dos principales rasgos bioquímicos relacionados con la neuropatología de EA son las marañas neurofibrilares formadas por agregación de proteína TAU hiperfosforilada, la cual en forma soluble lleva a toxicidad sináptica y neurodegeneración y las placas seniles que contienen el amiloide peptídico $\beta(A \beta)$, que como intermedio soluble es también perjudicial a la sinapsis (Zhang H, Ma, Zhang Y.-W y Xu, 2012).

Placas seniles que contienen el amiloide Aß. La proteína precursora de amiloide (APP), además de ser un receptor que envía señales a través del sistema de proteína $\mathrm{G}$, es la fuente del amiloide $A \beta$ encontrado en las placas neuríticas extracelulares de EA (Finder, 2010).

El procesamiento de APP para la obtención de $A \beta$ se da por dos vías denominadas amiloidogénica y no amiloidogénica mediante rompimiento secuencial por un grupo de enzimas llamadas alfa $(\alpha)$, beta $(\beta)$ y gama $(\gamma)$ secretasas. $\beta$-secretasa favorece la vía amiloidogénica produciendo la forma soluble de $\operatorname{APP}(\operatorname{sAPP} \beta)$ y un fragmento $C$ carboxi terminal ( $\beta$ APP-CTF), el cual es transformado por $\gamma$-secretase en el péptido $\mathrm{A} \beta$ y en el dominio intracelular de la proteína precursora de amiloide (AICD) (Chasseigneaux y Allinquant, 2012). Por la vía no amilodogénica $\alpha$-secretasa genera el fragmento soluble sAPP $\alpha$ y el fragmento $\alpha \mathrm{APP}-$ CTF, el cual es transformado por $\gamma$-secretase en A $\beta$ y AICD.
(Turner, O'Connor, Tate y Abraham, 2003). La $\gamma$-secretasa que interviene en la etapa final del procesamiento, produce el extremo $\mathrm{C}$ terminal de la $\mathrm{A} \beta$ y se adhiere a la región APP de la transmembrana donde puede generar un número de isomorfos con residuos entre 30-51 amino ácidos de longitud. Entre estos isomorfos A $\beta 1-40$ y A $\beta 1-42$ que comparten un terminal $\mathrm{N}$ pero difieren en su terminal carboxi son predominantes (Nicolas y Hassan, 2014; Zheng y Koo, 2006; Younkin, 1998; Jankowsky, et al., 2004). La actividad de la $\beta$-secretasa se atribuye a la proteína BACE1 y la de la $\gamma$-secretasa depende principalmente de la presenilina, nicastrina, APH-1 y PEN-2, las cuales forman un complejo proteolítico (Vassar, et al., 1999).

Bajo circunstancias no patológicas la trayectoria no amiloidogénica predomina a través de clivaje de APP por $\alpha-\gamma$-secretasas. Esta trayectoria forma $A \beta 1-40$ más pequeños, de solo 40 residuos en longitud, los cuales tienen menos probabilidad de agregarse y causar toxicidad. Bajo circunstancias patológicas, APP sufre clivaje mediante las $\beta-\gamma$ secretasas produciendo las especies más amiloidogénicas A $\beta 1-42$, que son las especies principales detectadas en los cerebros de pacientes de EA. A $\beta 1-42$ es considerado patogénico debido a su gran hidrofobicidad y mayor longitud de residuos (Jarrett, Berger y Lansbury, 1993; Iwatsubo, 1998; Finder, 2007).

Causas genéticas de EA. Se ha reportado que sobreproducción de A $\beta 1-42$ es causa de EA familiar y se especula que también de EA esporádico. La clonación de las proteínas presenilina (PS) y las mutaciones en PS1 y PS2 promueven el procesamiento de APP para formar el A $\beta$ amiloidogénico (Scheuner, et al., 1996). Los dos genes Presenilina 1 (PSEN1) y Presenilina 2 (PSEN2), que codifican respectivamente las proteínas presenilina 1 (PS1) y presenilina 2 (PS2), contribuyen al complejo secretasa. Mutaciones en estos genes se han identificado correlacionadas con EA porque se favorece el rompimiento proteolítico a través de $\beta$ - $\gamma$-secretasa (Younkin, 1998; Iwatsubo, 1998).

Además de los efectos tóxicos asignados principalmente a A $\beta 1-42$, los fragmento solubles $\operatorname{sAPP} \alpha$ y $\operatorname{sAPP} \beta$ pueden jugar un rol crítico en la disfunción cognitiva asociada con EA. sAPP $\alpha$ por ejemplo es neuroprotector, neurotrófico y regula la excitabilidad celular y plasticidad sináptica (Turner, et al., 2003).

Marañas neurofibrilares TAU. Fosforilación de la proteína TAU regula su unión a microtúbulos y está asociada a la denominada agregación TAU en EA. TAU se acumula en células neuronales y neuritas formando filamentos y marañas insolubles (NFTs) intracelulares (Iqbal, Fei, Cheng-Xin y Grundke-Iqbal, 2010).

La fosfoproteína TAU es la principal proteína asociada a microtúbulos (MAP) de una neurona madura. Su función está en la interacción con tubulina para promover el arreglo en microtúbulos, estabilizando la red microtubular. La actividad de TAU para esta función está regulada por su grado de fosforilación. En el caso de un cerebro EA, el nivel 
de fosforilación es 3 a 4 veces mayor que el de un adulto normal. Esta hiperfosforilación lleva a la desestabilización del ensamble microtubular y a la formación de marañas neurofibrilares (Iqbal, et al., 2010).

La hipótesis de "cascada amiloide" establece que la deposición de $A \beta$ en el cerebro es el evento que inicia la progresión de la enfermedad. Depósitos A $\beta$ activan mecanismos neurotóxicos incluyendo desregularización de las propiedades de enlace TAU-microtúbulos. Por otra parte la formación de marañas neurofibrilares TAU ha constituido otra hipótesis para explicar el origen de esta enfermedad (Hardy y Higgins, 1992).

La primera hipótesis está soportada por el hecho de que mutaciones implicadas en EA familiar aumentan las relaciones $\mathrm{A} \beta 42 / \mathrm{A} \beta 40$ y la agregación (Bentahir, et al., 2006; Nilsberth, et al., 2001; Suzuki N., et al., 1994). Entre los estudios basados en esta hipótesis vale la pena resaltar el rol de la acumulación de especies $A \beta$ oligoméricas solubles más bien que el de $\mathrm{A} \beta$ insoluble en las placas. Estas especies solubles pueden interaccionar con la función mitocondrial promoviendo un trastorno sináptico progresivo. El conocimiento exacto de este mecanismo posibilitaría el diseño de drogas preventivas para EA (Cavallucci, D'Amelio y Cecconi, 2012).

Aunque mutaciones TAU llevan a neurodegeneración ninguna de estas mutaciones está asociada a EA familiar (Spillantini, et al., 1998). Mutaciones TAU más bien causan otros problemas degenerativos donde están ausentes los depósitos de A $\beta 1-42$ (Lee, Goedert y Trojanowski, 2001; Oddo, et al., 2007).

Estrés oxidativo (EO). Radicales libres y especies reactivas de oxígeno (ROS) provienen del metabolismo celular aeróbico pero su efecto dañino al organismo normalmente es prevenido por el sistema antioxidante. Sin embargo un desbalance en el mecanismo de defensa antioxidante así como sobreproducción de radicales libres o exposición a éstos desde el ambiente lleva a EO (exceso de ROS). La toxicidad de los radicales libres contribuye al daño en proteínas y DNA, inflamación, daño en la piel y subsiguiente apoptosis celular. El EO está asociado a desordenes neurodegenerativos que llevan a las enfermedades de Alzheimer, Parkinson y otras [Uttara, Singh y Zamboni, 2009]. Por otra parte, la interrupción de vías metálicas homeostáticas por ROS lleva a niveles de calcio intracelulares aumentados que causan muerte celular neuronal.

Especies reactivas de oxígeno (ROS), incluyendo los radicales libres de anión superóxido $\left(\mathrm{O}_{2} \cdot\right)$, radicales hidroxil $(\mathrm{OH} \bullet)$, oxígeno singlete $\left(1 \mathrm{O}_{2}\right)$ y especies radicales no libres tales como peróxido de hidrógeno $\left(\mathrm{H}_{2} \mathrm{O}_{2}\right)$, son varias formas de oxígeno activado. Especies RNS, que también contribuyen $\mathrm{Al}$, son generadas cuando $\mathrm{O}_{2}$ reacciona con óxido nítrico $(\mathrm{NO} \bullet)$ para formar peroxinitrito (ONOO-), los cuales pueden formar otros RNS como dióxido de nitrógeno $\left(\mathrm{NO}_{2} \cdot{ }^{\bullet}\right.$ y peróxido de carbonato nitroso (ONOOCO2) (Cerutti, 1991; Fridovich, 1978). Las especies ROS y RNS resultan de reacciones biológicas oxidativas o factores exógenos.
Como la interacción de moléculas orgánicas con oxígeno es energéticamente desfavorable, la generación de ROS es prerrequisito del sistema metabólico para mediar tal interacción. El oxígeno está envuelto en el rompimiento de glucosa en la mitocondria (Mt) a través de fosforilación oxidativa, lo cual genera la fuente de energía de la célula: trifosfato de adenosina (ATP). La Mt tiene su propia maquinaria (Mt DNA) para la síntesis de enzimas y proteínas requeridas para la fosforilación oxidativa. Cualquier mutación en Mt DNA lleva a producción inapropiada de ATP y a perturbación en la cascada de fosforilación y bloqueo de la función neuronal (Kroemer y Reed, 2000). Los procesos metabólicos que utilizan oxígeno e iones metálicos redox (necesarios para la catálisis en la producción de ROS), en especial aquellos que envuelven altos niveles de ácidos grasos poli insaturados y sistemas con capacidad antioxidante relativamente pobre hacen que el cerebro sea vulnerable al EO (Kotebagilu, Vanitha y Urooj, 2015).

Toxicidad de Aß. Presencia de iones metálicos. La oxidación de sustratos orgánicos por hierro (II) y $\mathrm{H}_{2} \mathrm{O}_{2}$ es llamada "la química Fenton". Su eficiencia depende principalmente de la concentración de $\mathrm{H}_{2} \mathrm{O}_{2}$, relación $\mathrm{Fe}^{2+} /$ $\mathrm{H}_{2} \mathrm{O}_{2}$, pH y tiempo de reacción.

El principal efecto del EO en EA es la promoción de la formación de A $\beta$. Se han identificado varios mecanismos envueltos en esta formación, mediados por EO (Zhao y Baolu, 2013). Por otra parte $A \beta$ pertenece a un grupo de proteínas que capturan iones metálicos redox $\left(\operatorname{como~} \mathrm{Cu}^{2+}\right.$, $\mathrm{Fe}^{3+}$ y $\mathrm{Zn}^{2+}$ ) mediante coordinación a través de sus residuos de histidina en posiciones 6,13 y 14 y sus efectos derivados en EO pueden ser opuestos (Atwood, et al., 2003). A través de tal coordinación $\mathrm{A} \beta$ puede reducir los efectos de las especies ROS porque al asociarse con iones metálicos previene su participación en ciclos redox con otros ligandos (Zhao, et al., 2013), pero la unión con $\mathrm{Cu}^{2+}, \mathrm{Fe}^{3+}$ ocasiona también una reacción química tóxica, responsable de efectos neurotóxicos en EA, que envuelve reducción de los iones metálicos, producción de $\mathrm{H}_{2} \mathrm{O}_{2}$ y finalmente generación de radicales libres $\mathrm{OH} \bullet$ tóxicos (Opazo, Huang, y Cherny, 2002).

La toxicidad de $A \beta$ en EA ha sido también planteada recientemente como proveniente de la acumulación de oligómeros solubles presentes en equilibrio con las fibras insolubles de $A \beta$ considerando que ellos pueden provocar disfunción mitocondrial y promover deficiencia sináptica (Cavallucci, D'Amelio y Cecconi, 2012).

El zinc, como traza metálica más abundante en el cerebro, tiene funciones tanto benéficas como nocivas con respecto a EA. Benéficas ya que el zinc a través de las enzimas zinc metaloproteasas interviene en el proceso enzimático no amiloidogénico de las proteínas APP, así como en la degradación enzimática de especies monoméricas y oligoméricas de $A \beta$ que se forman en el proceso no amiloidogénico (Gough, Parr-Sturgess y Parkin, 2011). Nocivas porque el zinc se enlaza a $\mathrm{A} \beta$ promoviendo su agregación en especies neurotóxicas y ocasionando 
interrupción de la homeostasis del zinc en el cerebro, lo que da como resultado déficits sinápticos y de memoria (Borchardt, et al., 2000; Watt, Whitehouse y Hooper, 2011). Como mucha investigación sobre EA está orientada al desarrollo de inhibidores de la trayectoria amiloidogénica, la regulación de actividades de varias zinc metalloproteinasas representa una estrategia terapéutica a ser considerada (Watt, et al., 2011).

\section{Estrategias para el tratamiento de EA}

EA es una enfermedad multifactorial que requiere de estrategias terapéuticas complejas. En el tratamiento de EA se buscan agentes terapéuticos (principalmente provenientes de plantas) contra la pérdida neuronal ocasionada por procesos de EO y también para prevenir degeneración neuronal por estos mismos procesos. El carácter antioxidante de estos agentes se determina directamente por la capacidad para atrapar y neutralizar radicales libres y ROS e indirectamente por la habilidad para coordinarse con iones metálicos asociados con placas neuronales. Entre estos agentes son óptimos los antioxidantes naturales capaces de neutralizar radicales libres y ROS, y a la vez de secuestrar iones metálicos asociados con placas neuronales (Uttara, et al., 2009).

Popa-Wagner, et al., (2013) describen la terapia antioxidante como una nueva estrategia neuroprotectora en EA, donde la modulación del balance oxidante-prooxidante provee una acción terapéutica que puede ser usada para mejorar neuroprotección en respuesta al EO. Los polienoles y sus metabolitos, en vivo, no actúan solo como antioxidantes convencionales en EA, sino que también ejercen acciones de modulación en el sistema a través de una acción directa sobre varias vías de señalización, dependiendo de su estructura y de su concentración (Mansuri, Parihar P, Solanki y Parihar MS, 2014).

Antioxidantes. El EO como resultado del desbalance entre la formación de ROS y su neutralización mediante los antioxidantes biológicos puede hacer daños en biomoléculas esenciales tales como proteínas, DNA, y lípidos. Estos daños pueden causar lesiones celulares y muerte y exacerbar algunas enfermedades asociadas a la edad como el cáncer, la enfermedad cardiovascular, diabetes y neurodegeneración (Moskovitz, Yim y Choke, 2002; Fridovich, 1999; Gilgun-Sherki, Melamed y Offen, 2001). Los antioxidantes biológicos son moléculas naturales que pueden prevenir la formación incontrolada de radicales libres y especies ROS o inhibir sus reacciones con estructuras biológicas. Estos incluyen las enzimas antioxidantes tales como superóxido dismutasa (SOD), catalasa, y glutationa peroxidasa, así como pequeñas moléculas no enzimáticas como el ácido ascórbico, el ácido lipoico, polifenoles y carotenoides derivados de la dieta diaria; la célula sintetiza minoritariamente estas moléculas. Indirectamente agentes quelantes de metales redox ejercen acción antioxidante, previniendo su acción en la generación de radicales libres (Gilgun-Sherki, et al., 2001).
Acción antioxidante de polifenoles. En general los polifenoles ejercen su acción antioxidante a través del secuestro de especies de oxígeno activas tales como radical superoxido $\left(\mathrm{O}_{2} \cdot{ }^{\bullet}\right)$, peróxido de hidrogeno $\left(\mathrm{H}_{2} \mathrm{O}_{2}\right)$, radical hidroxil $(\mathrm{HO} \bullet)$, oxígeno singlete $\left(1 \mathrm{O}_{2}\right)$ y radicales peroxil $\left(\mathrm{RO}_{2} \bullet\right.$. Esta capacidad antioxidante se debe a su habilidad para donar átomos de hidrógeno y electrones a la molécula o especie oxidada y a la estabilidad de las especies formadas, $\mathrm{ArO} \bullet \mathrm{y} \mathrm{ArOH} \bullet+$.

La facilidad de formación y estabilidad de especies radicales $\mathrm{ArO} \bullet$ y $\mathrm{ArOH} \bullet+$ depende de sus rasgos estructurales: a. El número y posición en la estructura de grupos $\mathrm{OH}$. b. $\mathrm{La}$ asociación de grupos $\mathrm{OH}$ para formar enlaces de hidrógeno intramoleculares. c. La posibilidad, de acuerdo a su conformación, de permitir la deslocalización electrónica a través de la mayor parte de la molécula. La estabilización de $\mathrm{ArOH} \bullet+$ y $\mathrm{ArO} \bullet$ es el resultado de la deslocalización de los electrones no apareados en el anillo aromático por efectos de resonancia o hiperconjugación. Estos rasgos afectan la energía de disociación de los grupos $\mathrm{OH}$ y el potencial de ionización de $\mathrm{ArOH}$, los cuales determinan respectivamente la habilidad para donar átomos de hidrógeno y electrones (Munin y Edwards-Lévy, 2011).

Los polifenoles pueden actuar en terapias antioxidantes para EA no solo como eliminadores o secuestradores de radicales libres y especies ROS sino también a través de diferentes propiedades como asociación molecular con proteínas pro-oxidantes y como quelantes de iones metálicos $\mathrm{Fe}^{3+}, \mathrm{Al}^{3+}, \mathrm{Cu}^{2+}$ (Leopoldini, Russo y Toscano, 2011). Además, los polifenoles pueden presentar interacciones con la membrana plasmática, activar mensajeros secundarios y vías de señalización (de sobrevivencia y de muerte celular), tener efectos en la función mitocondrial, angiogenesis, modulación de enzimas metabólicas y autofagia (Velayutham, Babu y Liu, 2008; Chen, Z.P, Schell, Ho y Chen, K.Y, 1998; Braicu, Pilecki, Balacescu, Irimie Neagoe, 2011; Godoy, Rios, Zolezzi, Braidy e Inestrosa, 2014).

Capacidad antioxidante de (-)-(EGCG). El polifenol (-)-epigalo catequin -3-galato (EGCG) es un flavonoide tipo 3-flavanol que pertenece a la familia de las catequinas, las cuales presentan una estructura caracterizada por la presencia de dos o tres grupos $\mathrm{OH}$ en el anillo $\mathrm{B}$ y de dos grupos $\mathrm{OH}$ en posición meta (posiciones 5,7) del anillo A. Específicamente el EGCG posee 3 grupos $\mathrm{OH}$ en el anillo $\mathrm{B}$, dos grupos $\mathrm{OH}$ meta en el anillo A y un grupo galato en posición 3 del anillo benzopiránico heterocíclico $\mathrm{C}$. La figura 1 muestra su estructura.

La capacidad antioxidante de EGCG se debe a la habilidad para sobre regular las enzimas antioxidantes y para atrapar o eliminar especies ROS. Esta capacidad es conferida por los grupos $\mathrm{OH}$ en los anillos B y D. La sustitución 3',4',5'-tri 'hidroxilo del anillo B es importante en su habilidad como antioxidante y como secuestrador de radicales y el grupo galoil extra (anillo D) contribuye a mantener la efectividad en esta habilidad (Braicu, et al., 2010; Kondo, Kurihara, Miyata, Suzuki y Toyoda, 1999). 


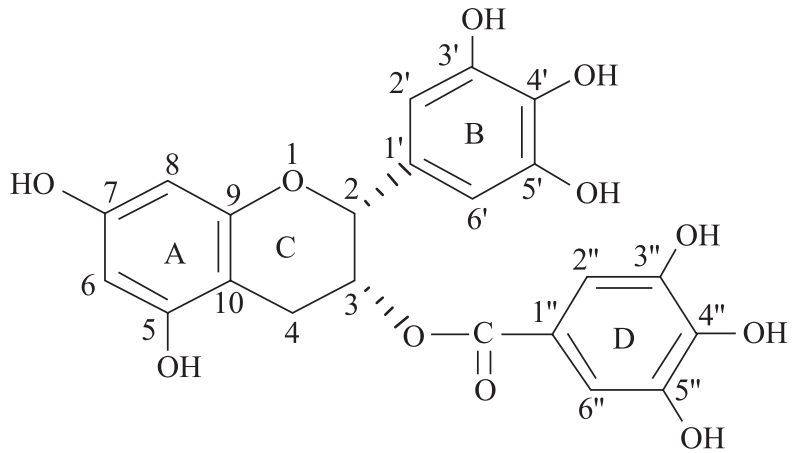

Figura 1. Estructura química de EGCG

Inhibición de daño oxidativo constituye un punto fundamental contra la adquisición de desórdenes neurodegenerativos. Los polifenoles y en particular EGCG ejercen este efecto controlando el EO mediante su acción como secuestradores de especies ROS y la modulación de la actividad de las enzimas envueltas en su control (Sonee, Sum y Wang, 1999; González-Manzano, et al., 2012; Swaran, 2009).

Quelación de metales. Se postuló en un principio que la quelación de metales podría tener beneficios en pacientes con EA a través de inhibición de la deposición de $\mathrm{Al}, \mathrm{Cu}, \mathrm{Zn}$ en el cerebro y/o inhibición de Fe para catalizar la formación de radicales hidroxilo tóxicos. Con relación al Al hasta ahora no hay conexión directa atribuible a los depósitos de $\mathrm{Al}$, encontrados en algunos estudios en pacientes con EA y el desarrollo de la enfermedad. Los resultados sobre Al permanecen controversiales debido a la complejidad de la química de Al en sistemas biológicos (Hegde, et al., 2009).

La adaptación de la terapia de quelación a las condiciones neurodegenerativas es una tarea compleja pero que ha sido abordada como tratamiento para EA. Un diseño de quelantes debe incluir aspectos de selectividad, afinidad, estabilidad, eliminación renal, forma de administración, y toxicidad (Hegde, et al., 2009).

Hay una evidencia creciente con relación a los lazos entre la di-homeostasis metálica en el cerebro y la aparición y progreso de EA. En etapas tempranas de EA, las concentraciones de $\mathrm{Fe}, \mathrm{Cu}, \mathrm{y} \mathrm{Zn}$ son elevadas, y por lo tanto sería útil la acción de un quelante que realmente disminuyera los niveles de estos metales, como también en etapas avanzadas un quelante para iones $\mathrm{Al}^{3+}$. En EA avanzado y severo el uso de quelantes puede llevar a una disminución de los elementos metálicos divalentes esenciales y empeorar la patología. Se debe establecer más sistemáticamente la deposición progresiva de metales con relación a la severidad de EA, lo cual determinará la posibilidad terapéutica de un quelante dependiendo del caso (Rao KSJ, Rao RV, Shanmugavelu y Menon, 1999).

Cherny RA, et al. (2001) encontraron que el quelante antibiótico CQ (5-cloro-7 iodo-8 hidroxiquinolina), el cual es específico para $\mathrm{Cu}$ y $\mathrm{Zn}$, puede inhibir la acumulación de A $\beta$. Treiber, et al. (2004) reportaron que tratamiento con $\mathrm{CQ}$ elevó significantemente la cantidad de $\mathrm{Cu}$ y $\mathrm{Zn}$, llegando a la conclusión que CQ no induce una disminución de la sobrecarga en estos metales acumulados, como se tenía planteado, aunque CQ es aparentemente capaz de reducir los depósitos $\mathrm{A} \beta$ en el cerebro, actuando al menos como molécula anti amiloidogénica pero no con los beneficios de un quelante metálico. A pesar de las controversias encontradas parece que CQ y algunos ligandos como la hidroxiquinolina son de beneficio significante en EA ya que pueden disminuir en pacientes la declinación cognitiva. Sin embargo no es claro si estos resultados son atribuibles a una atenuación de las interacciones $\mathrm{A} \beta /$ metal iónico o algún otro efecto. El CQ al menos puede presentar dos efectos en EA: como quelante y como antiamiloidogénico, bajo las condiciones presentes en el estudio anterior (Treiber, et al., 2004).

Ya que las alteraciones en EA predominantemente parecen provenir de la distribución perturbada de los metales esenciales y de las interacciones anómalas metal-proteína más bien que de la sobrecarga de metal, las terapias quelantes, que tienen metales como "blanco", deben utilizar quelantes con fuerza intermedia que favorezcan su redistribución y a la vez disminuyan o eliminen las interacciones metal -proteína (Rao, et al., 1999).

La capacidad antioxidante de un polifenol y en particular del EGCG también depende de su capacidad como quelante de metales tóxicos redox, previniendo su acción productora de ROS y a la vez reduciendo la carga metálica, considerada posible causa de EA.

EGCG actúa como quelante relativamente potente de $\mathrm{Fe}$ y $\mathrm{Cu}$, con los cuales se coordina a través de los grupos hidroxilo 3', 4',5' tanto del anillo B como del anillo D. La quelación con $\mathrm{Fe}$, puede tener efecto en el tratamiento de EA. Sin embargo para confirmar esta hipótesis se requiere mayor investigación conectada a resultados clínicos (Mandel, Amit, Bar-Am y Youdim, 2007).

Vías de señalización. Un rasgo esencial de los organismos multicelulares es el control coordinado de funciones celulares, a través de vías de señalización, donde señales producidas afectan células "blanco" o receptoras, lo cual se manifiesta en reacciones bioquímicas intracelulares que marcan la función fisiológica de la célula "blanco", objeto de ataque.

Hay dos formas principales por las cuales una célula "blanco" puede procesar una señal que entra: 1. A través de receptores celulares de superficie, en cuyo caso un receptor en la parte externa de la célula recibe la señal (ejemplo una sustancia mensajera) y desde allí se activa e inicia una cadena de señalización al interior de la célula. 2. El mensajero entra directamente a la célula "blanco" y activa el receptor. En ambos casos la señal representa información que es detectada por receptores específicos y convertida a respuesta celular, lo cual siempre envuelve un proceso químico. Más del 50\% de las drogas tienen como "blanco" tres tipos de proteínas: receptores acoplados a proteína G GPCR, $27 \%$, a receptores nucleares, $13 \%$ y a canales iónicos (13\%) (Krauss, 2008). 
La mitocondria es el conjunto de organelas metabólicas que combinan detección de nutrientes y vías de señalización de crecimiento para regular la salud, manteniendo producción de energía y homeostasis de $\mathrm{Ca}^{2+}$, y reducir la apoptosis. Las aproximaciones genéticas han identificado algunas vías de señalización que representan modificadores críticos de la función mitocondrial y que regulan procesos adversos a la salud y a la vida.

Mecanismos moleculares de EA y vías de señalización. Las vías bioquímicas o mecanismos que llevan a los efectos patológicos de EA, se describen como trayectorias de señalización inter, intra y extracelulares. Conocer las bases moleculares de estas vías y como ellas interaccionan dentro de las células, es importante en su utilización para disminuir o atenuar los déficits mitocondriales metabólicos, la hiperfosforilación de TAU, la reducción en sinapsis por la acumulación de $\mathrm{A} \beta$ y finalmente la muerte neuronal en EA (Godoy, et al., 2014).

Varias acciones inhibitorias o estimulantes de polifenoles en vías de señalización afectan grandemente las funciones celulares mediante alteración del estado de fosforilacion de moléculas "blanco". Además los polifenoles modulan también expresiones de genes a través de varios factores de transcripción (Cheng, Zhang y Lian, 2015). Spencer (2007) describe las interacciones de flavonoides con vías de señalización neuronales.

EGCG además de actuar directamente como antioxidante, también puede auto oxidarse y producir $\mathrm{H}_{2} \mathrm{O}_{2}$, en medio de cultivo con o sin células. Si bien a bajas concentraciones, ROS pueden actuar como mensajeros secundarios en algunas trayectorias o vías de transducción de señal neuroprotectoras (Suzuki YJ, Forman y Sevanian, 1997), a altas concentraciones pueden llevar a activar la muerte celular apoptótica (Schipper, 2004; Uttara, et al., 2009).

Las propiedades de EGCG como anti oxidante o pro oxidante son dependientes de concentración y del contexto celular. La estimulación de vías de señalización se da por la producción de especies de oxígeno y a través de mensajeros secundarios o directamente por interacción del EGCG con proteínas receptoras al interior de la célula "blanco". Esta estimulación es benéfica para EA (promueve mecanismos protectores celulares) cuando se tienen bajos niveles de especies ROS. Es citotóxico a concentraciones $>50 \mu \mathrm{M}$. De (1-2 $\mu \mathrm{M}$ hasta $10 \mu \mathrm{M})$ en EGCG, produce niveles más bajos de especies de oxígeno que estimulan múltiples vías de transducción de señales que promueven mecanismos protectores celulares (Kim H-S.,Quon y Kim J-a, 2014).

Vías de señalización de muerte celular en EA. EO conlleva a destrucción de membrana lipídica, clivaje de DNA, oxidación de proteínas y finalmente a apoptosis por vía: a. Intrínseca, mitocondrial, con aumento en proteínas pro-apoptóticas (PA): Bax, Bad, Bak y disminución en antiapoptóticas (AA): Bcl-2 y Bcl-xL de la familia Bcl-2 y caspasa $b$ extrínseca mediada por receptores de muerte. El factor de necrosis TNF- $\alpha$ interacciona con receptores de muerte como TNFR1 (Cheng, Zhang y Lian, 2015).
La modulación de EGCG de genes de sobrevivencia y muerte celular ocurre de forma dependiente de la concentración. A bajas concentraciones actúa como neuroprotector, reduciendo la expresión de genes pro-apoptóticos sin efecto en los antiapoptóticos. Adicionalmente, la declinación en expresión de bad y bax activa mensajeros secundarios que regulan la permeabilización de membrana mitocondrial, aumentando la relación de proteínas Bcl-2/Bcl-xL a Bax/ Bad. Altas concentraciones de EGCG inducen expresión de proteínas pro apoptóticas mas bien que antiapoptóticas (Singh, Mandal y Khan, 2016).

EO afecta el doblamiento de proteínas, en el retículo endoplásmico y activa vías UPR, ERAD, asociadas a estrés. Las proteínas de choque térmico (Hsp), pueden inhibir apoptosis como Hsp70 que posee la habilidad de prevenir agregación /oligomerización de $\mathrm{A} \beta$ /TAU o por el contrario pueden ser proapoptóticas como la Hsp90.

La sobre expresión de una Hsp, en particular Hsp70, sirve como rol protector en varios modelos diferentes de lesión en el sistema nervioso, pero ha sido también ligada a un rol perjudicial en algunas enfermedades.

El mecanismo de protección de Hsp70 se cree que está relacionado con su función acompañante llevando a protección contra doblamiento anómalo y agregación, previniendo estos efectos y manteniendo las proteínas en su trayectoria de doblamiento productiva. Los mecanismos específicos para esta protección no están bien entendidos pero probablemente son multifactoriales y comprenden un amplio rango de funciones chaperonas desde la prevención de la agregación de proteínas hasta la interferencia con varias cascadas de muerte. Las Hsp preferencialmente enlazan proteínas desdobladas o parcialmente dobladas pero no proteínas normales activas con la excepción de clatrina (Rui-Chun, et al., 2014).

En EA, inhibidores de Hsp90 pueden re direccionar formación de agregados neuronales, y proteger contra toxicidad por activación de HSF-1 y la subsiguiente inducción de proteínas de choque térmico como Hsp70. (Ou, Meng-Shan, An-Mu, Jin-Tai y Lan, 2014).

Vias de señalización de kinasas. Las kinasas modifican proteínas uniendo grupos fosfato de ATP a residuos ser, thr, tyr y hacen una transducción de señales (interacciones ligando/receptor y perturbación en el ambiente celular) desde la membrana hacia el interior de la célula. La activación de las vías de señalización Kinasas conlleva a la reprogramación de expresión de genes por regulación de factores de transcripción o de la estabilidad de mRNA o de la translación de proteínas. Regulan aspectos de función celular normal. Presentan efectos pro- y anti-apoptóticos en el sistema nervioso.

Estas vías incluyen PI3K (3 kinasa fosfoinositida), Akt (o proteína kinasa B), PTyrK (proteína tirosina), PKC (proteína kinasa C), MAPKs (proteínas kinasas activadas por mitógeno). Entre estas últimas están: ERK (kinasa regulada por señal extracelular), JNK (kinasa terminal c-Jun $\mathrm{NH}_{2}$ ), p38/ 
SAPKs (proteínas kinasa activadas por estrés), las cuales son activadas por estímulos extra e intracelular como factores de crecimiento peptídicos, citocinas, hormonas y estrés (EO y ER).

Desviación al control estricto de estas vías está implicada en el desarrollo de enfermedades de Alzheimer y Parkinson. Con efectos pro- y anti-apoptóticos en el sistema nervioso, la MAP y la PI3K juegan un rol importante en crecimiento, diferenciación y sobrevivencia neuronal. La activación de ERK, PI3K, Akt, PKC lleva a sobrevivencia celular. La activación de SAPK's, JNK's, p38 lleva a muerte celular (Kim E.K. y Choi E.J, 2010).

La proteína kinasa $\mathrm{C}$ (PKC) promueve la producción de la forma soluble de la proteína precursora de amiloides ( $\operatorname{sAP} \alpha$ ) obtenida vía la activación de $\alpha$-secretasa, reduciendo la acumulación de los niveles $A \beta$ patogénicos en el cerebro. Específicamente, la activación de KC $\alpha$ y de MAPK aumenta los sAPP $\alpha$ (Kim T., Hinton D.J. y Choi D-S, 2011).

EGCG ejerce efectos neuroprotectores mediados por la activación de la vía de señalización $\mathrm{PKC}$, induciendo liberación de sAPP $\alpha$ no amiloidogenico e inhibiendo la generación del péptido amiloide beta (Menard, Bastianetto y Quirion, 2013). Además de restablecer la actividad de la proteína kinasa PKC, EGCG inhibe la caspasa-3 y activa la vía PI3K/Akt e inhibe la expresión de genes proapoptóticos Bax y Bad e induce genes antiapoptóticos como Bcl-2, Bcl-W y Bcl-X (Piao, et al., 2011).

Señalización del factor de respuesta antioxidante Nrf2. Nrf2 (factor 2 relacionado con eritroide nuclear 2) es un factor de transcripción que se enlaza al elemento de respuesta antioxidante y regula la expresión de una batería de genes envueltos en la defensa antioxidante y antiinflamatoria como también en protección mitocondrial. Inflamación vía prolongada activación de kinasas p38 y kinasa sintasa glicógeno 3 beta (GSK-3b) y activación de histona deacetilasa da lugar a desregulación del sistema Nrf2. Prevenir patologías relacionadas con EO, a través de Nrf2, puede ser más efectivo que reversar patologías avanzadas.

La molécula señalizante se une al Nrf2 regulando su traslación al núcleo o su activación para enlazarse a elementos-cis: ARE (elemento de respuesta antioxidante) o EpRE (elemento de respuesta electrofílica) de enzimas antioxidantes. Nrf2 también se une en el núcleo a otros factores-trans: Maf-F/G/K y a coactivadores de ARE. La vía Nrf2-ARE provoca la activación de enzimas desintoxicantes y anti tóxicas como HO-1, GSH-Px y GST en la defensa celular contra el EO, ejerciendo un mecanismo citoprotector (Joshi y Johnson, 2012).

Un compuesto con alta potencia como electrófilo y oxidante, puede funcionar como activador de Nrf2 (asociado con Keap1), a través de la modificación de residuos de cisteína en Keap1, originando su liberación y translación al núcleo (Na y Surh, 2006). Además a través de su activación, las vías de señalización PKC, MAPKs, PI3K, PERK, Ck2, pueden fosforilar Nrf2, afectando el proceso de liberación de Nrf2 desde el complejo Nrf2-Keap1, así como la estabilidad y la translación de Nrf2 (Misra, et al., 2002). En contraste, p38MAPK puede estimular o inhibir la translación de Nrf2 dependiendo del tipo de célula.

Activación de Nrf2 puede representar una excelente estrategia terapéutica cuando EO y disfunción mitocondrial son rasgos patológicos claves. Sin embargo es también importante examinar la toxicidad potencial que las moléculas activadoras pueden exhibir especialmente con relación a la dosis (Esteras, Dinkova-Kostova y Abramov, 2016).

La activación de Nrf2 se considera un arma de doble filo, en pacientes con cáncer. Por una parte su activación previene EO o inflamación asociada con cáncer y por otra una sobreexpresión o una mayor relación Nfr2 citosólico/ nuclear puede llevar a la expresión de enzimas detoxificantes fase II y a la resistencia de células cancerígenas a ciertos medicamentos. El desarrollo de inductores ARE específicos e inhibidores Nrf2 constituye una esperanza para el tratamiento de cáncer, enfermedades crónicas y toxicidad (Pasello, et al., 2008).

Cuando EGCG estimula producción de bajos niveles de ROS y $\mathrm{H}_{2} \mathrm{O}_{2}$, causa activación del factor redox sensible 2 (Nrf2) relacionado con NF- $\kappa$ B y NF-E2 llevando a aumentar la expresión de las enzimas antioxidantes HO-1 y glutationa (Kim H-S, Quon y Kim J-a, 2014). La activación de Nrf2 por EGCG ha sido demostrada en varios tipos de células (Kou, Kirberger, Yang y Chen, 2013). Wu C.C, et al., (2006), observaron inducción de la enzima HO-1 en células endoteliales debido a la activación de Akt y Nrf2 por EGCG, lo cual imparte protección de células endoteliales contra $\mathrm{H}_{2} \mathrm{O}_{2}$ mediada por EO. En cultivo de neuronas de ratón (H 19-7), EGCG aumentó la expresión de HO-1 mediante activación de del factor de transcripción Nrf2, mostrando protección contra muerte celular inducida por EO (Romeo, et al., 2009).

Señalización del factor $\mathbf{N F}-\boldsymbol{k} \boldsymbol{B}$. NF- $\mathrm{\kappa B}$ es una familia de factores de transcripción que protegen las células contra la apoptosis provocada por daño en el DNA. Regulan genes relacionados con EO, inflamación y apoptosis. Pueden participar en varias vías produciendo efectos protectores o dañinos dependiendo del ligando unido y de su activación o inhibición. Una lista de señales que pueden activar NF-kB en neuronas incluyen: factor de necropsia (TNF), glutamato neurotransmisor excitatorio, factor de crecimiento neural (NGF), factor neutrófico dependiente de la actividad (ADNF), una forma secretada de la proteína precursora de amiloide, y moléculas de adhesión celular (Mattson y Meffert, 2006).

NF-kB puede activarse a través de cascadas kinasas incluyendo calcio/ kinasa dependiente de calmodulina, Akt y PKC (Ansari y Khodagholi, 2013).

La actividad de NF-kB y la expresión de varios genes blanco de NF-kB son alteradas en asociación con la patología cerebral en EA. Niveles de reactividad inmune p65 son 
aumentados en neuronas y astrocitos asociados con placas amiloideas, sugiriendo activación aumentada de NF-kB. Exposición de neuronas a $\mathrm{A} \beta$ induce activación de NF-kB.

Regulación negativa de NF- $\kappa \mathrm{B}$ favorece la disminución de proteínas proapoptóticas Bcl-2. Inhibición de la actividad de transcripción de NF-kB resulta en vulnerabilidad aumentada de las neuronas a la muerte inducida por $\mathrm{A} \beta$. Por otra parte activación de NF-kB puede prevenir la muerte de neuronas, induciendo la producción de proteínas anti apoptóticas tales como Bcl-2, IAPs y manganeso superóxido dismutasa (Mn-SOD).

El reto más importante es si aumentar o inhibir la activación de NF-kappa B. Los factores que determinan si la activación de NF-kB es benéfica o perjudicial para las neuronas en el contexto de desórdenes neurodegenerativos no son claros hasta ahora pero probablemente envuelven elementos regulatorios que determinan si NF-kB aumenta la expresión de genes pro o antiapoptóticos (Mattson, et al., 2006).

EGCG ( $3 \mathrm{mg} / \mathrm{kg}$ en agua potable) inhibió apoptosis en cerebro de ratones, inyectados con A $\beta 1-42$, mediante inhibiciòn de ERK y NF- $\mathrm{B}$ (Lee, et al., 2009).

Vias de señalización metabólicas Wnt, AMPK, y mTOR. Estas vías son capaces de modular reducción de amiloide $\mathrm{A} \beta$, regulación de la dinámica de la mitocondria y disponibilidad de energía neuronal.

AMPK: 5 '-Proteína kinasa activada por 5 '- adenosina monofosfato. Sensor metabólico que modula el ATP intracelular. Es activada como respuesta al estrés que agota el suministro de ATP. Su actividad disminuye en EA, indicando disminución en la biogénesis de la mitocondria, por generación de $\mathrm{A} \beta \mathrm{y}$ fosforilación de TAU. Regula vías enzimáticas como la lipólisis y vías glicolíticas, mediante fosforilación directa de enzimas y acción de factores de transcripción, co-activadores y co-represores.

El agente señalizante, dependiendo de su hidrofobicidad se une a un receptor de superficie o a un receptor en el citoplasma.

No es claro el rol de AMP en EA debido a que aumento en la actividad de AMPK lleva a disminución de mTOR, facilitando autofagia y degradación lisosomal de A $\beta$. Por otra parte la activación de AMPK no es neuroprotectora por que puede llevar a generación de $\mathrm{A} \beta \mathrm{y}$ fosforilaciòn de TAU (Cai, Yan, Li, Quazi y Zhao, 2012). Perturbación en mTOR afecta múltiples vías, incluyendo el metabolismo de glucosa, producción de energía, función mitocondrial, crecimiento celular y autofagia. Ataque de mTOR en el sistema nervioso central CNS ofrece perspectivas en estudios de drogas para EA. Sin embargo se necesitan más estudios para entender su relación con las múltiples señales envueltas en EA (Wang, et al., 2014).

Vias de señalización Wnt: Wnt//3-catenina; Wnt/Ca ${ }^{2+}$; de polaridad celular planar PCP. Wnt son proteinas que pertenecen a una familia de proteínas secretadas glicosiladas ricas en cisteina, denominadas así después de la identificación de la proteína "wingless" de drosofila y de la proteína "Int1 "de ratón.
La mayoría de organismos contienen múltiples genes Wnt. La vía Wnt, presenta un rol critico en sobrevivencia celular, desarrollo embrional y actividad sináptica. Disfunción Wnt inducida por $\mathrm{A} \beta$ ha sido detectada en EA y está asociada con degeneración neuronal y desarreglo sináptico, lo que sugiere una relación fuerte entre trastorno EA y desajuste Wnt. (Wan, Xia, Kalionis, Liu y Li, 2014).

La activación de Wnt vía $\beta$-catenina da protección contra $\mathrm{Ab}$ y a la vez contra TAU hiperfosforilado mejorando eficacia cognitiva en EA. En Wnt/ $\beta$-catenina, el ligando Wnt interacciona con el receptor Frizzled y el coreceptor LRP5/6 para activar la proteina Dishevelled (Dvl). Con esta activación se da fosforilación de beta catenina con su consecuente translación al núcleo para expresar genes de Wnt. En ausencia de Wnt, la enzima kinasa sintasa glicógeno 3 (GSK3) fosforila la beta catenina en su terminal $\mathrm{N}$ para luego ser degradada por la enzima proteosoma, con lo cual se desactiva la vía Wnt (Inestrosa y Varela-Nallar, 2014). Además, GSK-3 $\beta$ es una de las kinasas serina/treonina (Ser/ Thr) más importantes que no solamente desactiva Wnt, sino que fosforila MAP TAU, llevando a la formación de ovillos neurofibrilares TAU. La sobre activación de GSK3 lleva a un aumento en los rasgos patológicos de EA y por lo tanto se plantea como hipótesis que inhibidores de la actividad de GSK 3 proporcionan una nueva estrategia para tratamiento de EA (Hooper, Killic y Lovestone, 2008). Amplia evidencia sugiere que la patología A $\beta$ precede la patología TAU. Sin embargo el mecanismo por el cual $A \beta$ induce hiperfosforilación TAU aun no es claro. Estudios recientes muestran que Wnt puede superar el gap entre las dos patologías, donde GSK-3 $\beta$ es un mediador importante en la producción de los productos patológicos (Wan, et al., 2014).

Exposición de neuronas a $\mathrm{A} \beta$ aumenta la actividad GSK3 $\beta$ a través de la inhibición de la vía de señalización kinasa PI3K. Por otra parte el bloqueo en la expresión o actividad de GSK3$\beta$ previene la neurodegeneración inducida por $\mathrm{A} \beta$. Una activación persistente de la vía Wnt a través de ligandos Wnt o mediante inhibición de GSK-3 $\beta$ o del también regulador negativo Dickkopf-1 (DKK-1) es capaz de proteger contra la toxicidad $\mathrm{A} \beta$ y mejorar la habilidad cognitiva en AD (Takashima, et al., 1996).

Cualquier desbalance en la vía Wnt (mucho o muy poco) conduce a enfermedad. El crecimiento de células en cáncer es un ejemplo de sobre activación de esta vía. Científicos de la clínica Mayo en EEUU reportan el descubrimiento de un defecto clave en un nuevo modelo de ratones que lleva a la supresión de la vía de señalización Wnt en EA. Estos resultados explican porque pacientes con cáncer, donde esta vía por el contario se sobre activa, tienen bajo riesgo de adquirir EA y viceversa. Inhibidores de esta trayectoria son eficientes para el tratamiento de cáncer pero no podrían ser aplicados a personas con EA o riesgo de adquirirlo. Más aun este hallazgo puede ser útil para EA en el sentido de aprender como restablecer esta vía mediante compuestos o moléculas pequeñas, sin inducir efectos laterales (Punsky Kevin, 2014). 
EGCG se ha encontrado ser antagonista de la vía de señalización Wnt/ $\beta$-catenina de células cancerígenas de CRC y de mama (Tarapore, Siddiqui y Mukhtar, 2012). En contraste EGCG in células neuronales N18D3, suprime apoptosis inducida por estrés provocado por radical-oxidativo, a través de varios mecanismos como son la activación de la vía antiapoptótica dependiente de (PI3K)/Akt y la inhibición de la actividad de kinasa-3- (GSK-3) (Koh, et al., 2004).

Señalización en $\mathrm{EA}$ relacionada directamente con enzimas. La expresión de enzimas como superóxido dismutasa y glutationa peroxidasa disminuyen el EO. Desbalance entre las proteínas kinasas fosforilizantes y las proteínas fosfatasas desforilizantes lleva a fosforilaciòn de TAU excesiva. La proteina kinasa sintasa glicógeno $3 \beta$ (GSK$3 \beta)$ y la proteina kinasa 5 divisora de células (CDK5) son importantes en esta hiperfosforilación. EGCG ejerce un mecanismo neuroprotector primero inhibiendo la formación de $\mathrm{A} \beta$ mediante inhibición del proceso proteolítico APP y segundo inhibiendo la translocación al núcleo del complejo cAbl/FE65 y la activación de GSK3 (Lin Ch-Li, Chen, Chiu, Way y Lin J-K, 2009).

Además de la activación o inhibición de las proteínas kinasas, efectos en la patología de EA se dan mediante modificación en la acetilación y glicación de las proteínas, lo cual provoca cambios en las actividades de las enzimas. La enzima acetil colinesterasa reduce la degradación de acetil colina AChE, lo que lleva a su aumento y a pérdida de neuronas colinérgicas. Donepezil, galantamina, rivastigmina, tacrina, memantina son drogas aprobadas por la FDA como inhibidores de la enzima acetil colinesterasa (Alzheimer's Association, 2016).

EGCG reduce AChE, llevando a su disminución (Ansari, et al., 2013). La memantina está aprobada por la FDA como antagonista de N-metil-D-aspartato (NMDA), el cual está asociado con influjo de calcio, producción de ROS, disfunción mitocondrial, déficit de memoria y aprendizaje y otros trastornos relacionados con neuronas corticales (Geerts y Grossberg, 2006).

Nuevas aproximaciones de transporte de medicamentos para EA a través de la barrera sanguínea cerebral (BBB). De acuerdo a los estudios señalados en esta revisión, EGCG es un buen candidato como agente neuroprotector en el tratamiento de EA. No obstante hay limitaciones para un transporte eficiente a través de la BBB por su pobre biodisponibilidad debido a su solubilidad y estabilidad, especialmente cuando es administrado por vía oral. Factores tales como temperatura, luz, $\mathrm{pH}$ del estómago, procesos enzimáticos, tiempo de absorción restringida y transporte a través de la BBB insuficiente limitan los atributos de un medicamento como EGCG.

La nanotecnología basada en sistemas de liberación controlada de medicamentos puede superar estas limitaciones. Sistemas de nano partículas, con tamaños menores de $200 \mathrm{~nm}$, preparadas a partir de materiales biocompatibles, con capacidad de carga del medicamento apropiada, vienen siendo ampliamente estudiados para el tratamiento de diversas enfermedades, con ventajas en cuanto a la disminución de efectos laterales y alta biodisponibilidad del medicamento en el sitio. Al quitosano o a sus derivados oligosacáridos (COS) se les ha atribuido propiedades neuroprotectoras (Khodaghol, Eftekharzadeh, Maghsoud y Rezaei, 2010).

Nuestro grupo de investigación viene incursionando en este tema y ha logrado preparar nano partículas del biopolímero biodegradable quitosano, funcionalizadas con el anticuerpo monoclonal OX26, capaces de traspasar la BBB (Monsalve, et al., 2015). Estas nano partículas serán utilizadas para el encapsulamiento de polifenoles y su posterior estudio en el tratamiento de EA.

Los efectos combinados quitosano/polifenoles no han sido reportados en el tratamiento de EA. Con esta combinación, además de la eficiencia aumentada del polifenol transportado en nano partículas de quitosano, podrían obtenerse resultados más positivos que los esperados en el tratamiento de EA con polifenoles no nanotransportados.

\section{Conclusiones}

El EO es un rasgo patológico común a muchas enfermedades neurológicas. La producción de especies reactivas de oxìgeno (ROS) es el principal mecanismo envuelto en el desbalance redox celular. Los antioxidantes protegen las células contra los ROS, por lo que han sido considerados como agentes terapéuticos atractivos para contrarrestar el daño neuronal. Por otra parte a través de una producción ROS moderada, una droga para el tratamiento de EA puede activar vías de señalización que promueven efectos positivos.

En el caso de los polifenoles, teóricamente considerados como antioxidantes por su habilidad para disminuir los niveles ROS y que han mostrado gran potencialidad en el tratamiento de EA, tres respuestas relacionadas con auto producción de ROS parecen resultar de la exposición de las células a ellos. Estas respuestas dependen de la concentración y de la naturaleza prooxidante de los polifenoles. (a) Una exposición suave causa estrés oxidativo suave y activa el sistema antioxidante celular. (b) Una exposición de intermedia a alta, arrolla gradualmente el sistema antioxidante defensivo e induce muerte celular apoptótica. (c) Una exposición muy alta rápidamente sobrepasa las defensas antioxidantes y causa muerte celular por necrosis. Cuando se diseñan experimentos para identificar EO, como mecanismo causante de citotoxidad, un balance cuidadoso es necesario entre los ROS generados y la variable experimental (secuestrador o potenciador de toxicidad ROS) que media el EO. Para el tratamiento de enfermedades neurológicas, el uso de compuestos capaces de modular la producción ROS o capaces de impulsar la maquinaria de defensa antioxidante endógena por ejemplo activando la vía Nrf2 constituyen una aproximación para combatir el EO en el sistema central nervioso CNS (Carvalho, Firuzi, Gama, van Horssen y Saso, 2016). 
A través de vías de señalización como la Nrf2, algunas vías que envuelven proteínas kinasas, la vía NF-kB y las vías metabólicas Wnt, AMPK, y mTOR pueden haber efectos positivos en el tratamiento de EA.

La proteína kinasa $\mathrm{C}(\mathrm{PKC})$ promueve la producción de la forma soluble de la proteina precursora de amiloides $(\operatorname{sAPP} \alpha)$ obtenida vía la activación de $\alpha$-secretasa, reduciendo la acumulación de los niveles $A \beta$ patogénicos en el cerebro. Específicamente, la activación de PKCa y de MAPK aumentan los SAPP $\alpha$. Con efectos pro- y anti-apoptóticos en el sistema nervioso, la MAP y la PI3K juegan un rol importante en crecimiento, diferenciación y sobrevivencia neuronal. La activación de ERK, PI3K, Akt, PKC lleva a sobrevivencia celular.

Inhibición de la actividad de transcripción de NF-kB resulta en vulnerabilidad aumentada de las neuronas a la muerte inducida por $\mathrm{A} \beta$. Por otra parte activación de NF$\mathrm{kB}$ puede prevenir la muerte de neuronas, induciendo la producción de proteínas anti apoptóticas tales como $\mathrm{Bcl}-2$, IAPs y manganeso superóxido dismutasa (Mn-SOD).

La vía Wnt, presenta un rol critico en supervivencia celular, desarrollo embrional y actividad sináptica. Disfunción Wnt inducida por $\mathrm{A} \beta$ ha sido detectada en EA y está asociada con degeneración neuronal y desarreglo sináptico, lo que sugiere una relación fuerte entre trastorno EA y desajuste Wnt. La activación de Wnt vía $\beta$-catenina da protección contra Ab y a la vez contra TAU hiperfosforilado mejorando eficacia cognitiva en EA. Es importante tener en cuenta que cualquier desbalance en la vía Wnt (mucho o muy poco) conduce a enfermedad. El crecimiento de células en cáncer es un ejemplo de sobre activación de esta vía. Inhibidores de esta trayectoria son eficientes para el tratamiento de cáncer pero no podrían ser aplicados a personas con EA o riesgo de adquirirlo. Más aun este hallazgo puede ser útil para EA en el sentido de aprender como restablecer esta vía mediante compuestos o moléculas pequeñas, sin inducir efectos laterales.

En los estudios de medicamentos para el tratamiento de Alzheimer y enfermedades neurodegenerativas se encuentra que a pesar de los resultados positivos obtenidos in vitro y en experimentación preclínica, la eficacia a nivel clínico es marginal y con resultados en la mayoría de los casos lejos de los esperados. Esto puede ser debido en parte a la necesidad de un ajuste en concentraciones y en tiempo entre los estudios preclínicos y los clínicos. Por otra parte, métodos de liberación eficientes deben ser investigados, particularmente teniendo en cuenta que un agente terapéutico para enfermedades neurológicas debería cruzar la BBB (Carvalho, et al., 2016). La nanotecnología basada en sistemas de liberación controlada puede posibilitar el paso del medicamento a través de esta barrera.

\section{Conflicto de intereses}

La autora declara no tener conflicto de intereses.

\section{Referencias}

Alzheimer's Association. 2016. alz.org/research, Http.www.alz. org/research/science/alzheimer_disease_treatments.asp
Ansari Niloufar and Fariba Khodagholi. 2013. Natural Products as Promising Drug Candidates for the Treatment of Alzheimer's Disease: Molecular Mechanism Aspect. Curr. Neuropharmacol., 11 (4): 414-429.

Atwood C.S., Obrenovich M.E., Liu T., Chan H., Perry G., Smith M.A., Martins R.N. 2003 . Amyloid- $\beta$ : a chameleon walking in two worlds: a review of the trophic and toxic properties of amyloid- $\beta$. Brain Res. Brain Res. Rev. 43 (1): $1-16$.

Ballard C., Gauthier S., Corbett A., Brayne C., Aarsland D., Jones E. 2011. Alzheimer's disease. Lancet, 377: 1019-31.

Bentahir M., Nyabi O., Verhamme J., Tolia A., Horre K., Wiltfang J., Esselmann H., de Strooper B. 2006. Presenilin clinical mutations can affect gamma-secretase activity by different mechanisms. J. Neurochem., 96: 732-742.

Borchardt T., Schmidt C., Camarkis J., Cappai R., Masters C.L., Beyreuther K., Multhaup G. 2000. Differential effects of zinc on amyloid precursor protein (APP) processing in copper-resistant variants of cultured Chinese hamster ovary cells. Cell Mol. Biol. (Noisy-le-Grand, France), 46 (4): 785-95.

Braicu C., Rugina D., Chedea V.S., Tudoran O., Balacescu O., Neagoe I, Socaciu, C. 2010. Protective action of different natural flavan-3-ols against aflatoxin B1-related cytotoxicity. J. Food Biochem., 34: 595-610.

Braicu Cornelia, Pilecki Valentina, Balacescu Ovidiu, Irimie Alexandru \& Ioana Berindan Neagoe. 2011. The Relationships Between Biological Activities and Structure of Flavan-3-ols. Int. J. Mol. Sci., 12: 9342-9353.

Cai Z., Yan L.J., Li K., Quazi S.H., Zhao B. Roles of AMPactivated protein kinase in Alzheimer's disease. (2012). Neuromolecular Med., 14 (1): 1-14.

Carvalho A.N., Firuzi O., Gama M.J., van Horssen J., Saso L. 2016. Oxidative stress and antioxidants in neurological diseases: is there still hope? Drug Des. Devel. Ther., 10: 23-42.

Castellani R. J., Zhu X., Lee H.-G., Smith M. A., \& G. Perry. 2009. Molecular pathogenesis of Alzheimer's disease: reductionist versus expansionist approaches, Int. J. Mol. Sci., 10 (3): 1386-1406.

Cavallucci V., D'Amelio M., Cecconi F. 2012. A $\beta$ toxicity in Alzheimer's disease. Mol. Neurobiol., 45 (2): 366-78.

Cerutti P. A. (1991). Oxidant stress and carcinogenesis. Eur. J. Clin. Invest., 21 (1): 1-5.

Chasseigneaux S., \& B. Allinquant. 2012. Functions of A $\beta$, sAPP $\alpha$ and $\operatorname{sAPP} \beta$ : similarities and differences. J. Neurochem., 120 (S1): 99-108.

Cheng Xuan, Lu Zhang, and Ya-Jun Lian. 2015. Molecular Targets in Alzheimer's disease: From Pathogenesis to Therapeutics. Bio. Med. Research International, Article ID 760758, 6 pages.

Chen Z.P., Schell J.B., Ho C.T., Chen K.Y. 1998. Green tea epigallocatechin gallate shows a pronounced growth inhibitory effect on cancerous cells but not on their normal counterparts. Cancer Lett., 129 (2): 173-9.

Cherny R.A., Atwood C.S., Xilinas M.E., Gray D.N., Jones W.D., McLean C.A., Barnham K.J., Volitakis I., Fraser F.W., Kim Y., Huang X., Goldstein L.E., Moir R.D., Lim J.T., Beyreuther K., Zheng H., Tanzi R.E., Masters C.L., Bush A.I. 2001. Treatment with a copper-zinc chelator markedly and rapidly inhibits $\beta$-amyloid accumulation in Alzheimer's disease transgenic mice. Neuron, 30: 665-676. 
Esteras Noemí, Dinkova-Kostova Albena T. and Abramov Andrey Y. 2016. Nrf2 activation in the treatment of neurodegenerative diseases: a focus on its role in mitochondrial bioenergetics and function. Biol. Chem., 397 (5): $383-400$

Finder, V. H. and R Glockshuber. 2007. Amyloid-beta aggregation. Neurodegenerative Diseases, 4: 13-27.

Finder, V. H. 2010. Alzheimer's disease a general introduction and pathomechanism. J. Alzheimers Dis., 22 (3): 5-19.

Fridovich.I. 1978. The biology of oxygen radicals. Science, 201 (4359): 875-80.

Fridovich. I. 1999. Fundamental aspects of reactive oxygen species, or what's the matter with oxygen. Ann. $N$ Y. Acad. Sci., 893: 3-18.

Geerts H, Grossberg G.T. 2006. Pharmacology of acetylcholinesterase inhibitors and N-methyl-D-aspartate receptors for combination therapy in the treatment of Alzheimer's disease. J. Clin. Pharmacol., 46 (7 S1): 8S-16S.

Gilgun-Sherki Y., Melamed E., Offen D. 2001. Oxidative stress induced-neurodegenerative diseases: the need for antioxidants that penetrate the blood brain barrier. Neuropharmacology, 40: 959-975.

Godoy Juan A., Juvenal A. Rios, Juan M. Zolezzi, Nady Braidy \& Nibaldo C. Inestrosa. 2014. Signaling pathway cross talk in Alzheimer's disease. Cell Communication and Signaling, 12: 23.

González-Manzano Susana, Ana M. González-Paramás, Laura Delgado, Simone Patianna, Felipe Surco-Laos, Montserrat Dueñas, \& Celestino Santos-Buelga. 2012. Oxidative Status of Stressed Caenorhabditis elegans Treated with Epicatechin. J. Agric. Food Chem., 60 (36): 8911-8916.

Gough Mallory, Parr-Sturgess Catherine, \& Edward Parkin. 2011. Review Article Zinc Metalloproteinases and Amyloid Beta-Peptide Metabolism: The Positive Side of Proteolysis in Alzheimer's disease. Biochemistry Research International, Article ID 721463, 13 pages.

Hardy J.A., Higgins G.A. 1992. Alzheimer's disease: the amyloid cascade hypothesis. Science, 256: 184-185.

Hegde Muralidhar L., P. Bharathi, Anitha Suram, Chitra Venugopal, Ramya Jagannathan, Pankaj Poddar, Pullabhatla Srinivas, Kumar Sambamurti, Kosagisharaf Jagannath Rao, Janez Scancar, Luigi Messori, Luigi Zecca, \& Paolo Zatta. 2009. Challenges Associated with Metal Chelation Therapy in Alzheimer's Disease. $J$. Alzheimers Dis., 17 (3): 457-468

Hooper C., Killick R., Lovestone S. 2008. The GSK3 hypothesis of Alzheimer's disease. J. Neurochem. 104 (6): 1433-9.

Inestrosa Nibaldo C., \& Varela-Nallar Lorena. 2014. Wnt signaling in the nervous system and in Alzheimer's disease. Journal of Molecular Cell Biology. 6: 64-74.

Iqbal Khalid, Fei Liu, Cheng-Xin Gong, \& Inge Grundke-Iqbal. 2010. Tau in Alzheimer Disease and Related Tauopathies. Curr. Alzheimer Res. 8: 656-664.

Iwatsubo, T. 1998. Abeta42, presenilins, and Alzheimer's disease. Neurobiology of Aging. 19: S11-3.

Jankowsky J.L., Fadale D.J., Anderson J., Xu G.M., Gonzales V., Jenkins N.A., Copeland N.G., Lee M.K., Younkin L.H., Wagner S.L.,Younkin S.G., Borchelt D.R. 2004. Mutant presenilins specifically elevate the levels of the 42 residue beta-amyloid peptide in vivo. Evidence for augmentation of a 42-specific gamma secretase. Human Molecular Genetics. 13: 159-70.
Jarrett J.T., Berger E. P. \& P. T. Lansbury, Jr. 1993. The carboxy terminus of the beta amyloid protein is critical for the seeding of amyloid formation: implications for the pathogenesis of Alzheimer's disease. Biochemistry. 32: 4693-7.

Joshi Gururaj \& Jeffrey A. Johnson. 2012. The Nrf2-ARE pathway: a valuable therapeutic target for the treatment of neurodegenerative diseases. Recent Pat CNS Drug Discov., 7 (3): 218-229.

Karunaweera Niloo, Raju Ritesh, Gyengesi Erika \& Münch Gerald. 2015. Plant polyphenols as inhibitors of NF-kB induced cytokine production- a potential anti-inflammatory treatment for Alzheimer's disease. Frontiers in Molecular Neuroscience, 8: 24.

Khodagholi Fariba, Eftekharzadeh Bahareh, Maghsoudi, Rezaei Nader Parisa Fathi. 2010. Chitosan prevents oxidative stress-induced amyloid $\beta$ formation and cytotoxicity in NT2 neurons: involvement of transcription factors Nrf2 and NF-Kb. Molecular and Cellular Biochemistry. 337 (1): 39-51.

Kim Eun Kyung, Choi Eui-Ju. 2010. Pathological roles of MAPK signaling pathways in human diseases. Biochimica et Biophysica Acta. 1802: 396-405.

Kim Hae-Suk, Quon Michael J., Kim Jeong-a. 2014. New insights into the mechanisms of polyphenols beyond antioxidant properties; lessons from the green tea polyphenol, epigallocatechin 3-gallate. Redox Biology. 2: 187-195.

Kim Taehyun, Hinton David J., \& Choi Doo-Sup. 2011. Protein Kinase C-Regulated A $\beta$ Production and Clearance. International Journal of Alzheimer's disease, (2011), Article ID 857368, 7 pages.

Koh S.H., Kim S.H., Kwon H., Kim J.G., Kim J.H., Yang K.H., Kim J., Kim S.U., Yu H.J., Do B.R., Kim K.S., Jung H.K. 2004. Phosphatidylinositol-3 kinase/Akt and GSK-3 mediated cytoprotective effect of epigallocatechin gallate on oxidative stress-injured neuronal-differentiated N18D3 cells. Neurotoxicology. 25 (5): 793-802.

Kondo K., Kurihara M., Miyata N., Suzuki T., Toyoda M. 1999. Scavenging mechanisms of (-)-epigallocatechin gallate and $(-)$-epicatechin gallate on peroxyl radicals and formation of superoxide during the inhibitory action. Free Radic. Biol. Med. 27 (7-8): 855-863.

Kotebagilu Namratha Pai, Vanitha Reddy Palvai \& Asna Urooj. 2015. Ex Vivo Antioxidant Activity of Selected. Medicinal Plants against Fenton Reaction-Mediated Oxidation of Biological Lipid Substrates, Article ID 728621, 7 pages.

Kou Xianjuan, Kirberger Michael, Yang Yi, Chen Ning. 2013. Natural products for cancer prevention associated with Nrf2-ARE pathway. Food Science and Human Wellness, 2 (1): 22-28.

Krauss, Gerhard. 2008. Biochemistry of Signal Transduction and Regulation. Wiley-VCH, p. 15. ISBN 978-3527313976

Kroemer G. and Reed J.C. 2000. Mitochondrial control of cell death. Nat. Med. 6 (5): 513-519.

Lee J.W., Lee Y.K., Ban J.O., Ha T.Y., Yun Y.P., Han S.B., Oh K.W., Hong J.T. 2009. Green tea (-)-epigallocatechin-3gallate inhibits beta-amyloid-induced cognitive dysfunction through modification of secretase activity via inhibition of ERK and NF-kappaB pathways in mice. J. Nutr. 139 (10): 1987-93.

Lee V.M., Goedert M., Trojanowski J.Q. 2001. Neurodegenerative tauopathies. Annu. Rev. Neurosci. 24: 1121-1159. 
Leopoldini M., Russo N., Toscano M. 2011. The molecular basis of working mechanism of natural polyphenolic antioxidants. Food Chem. 125: 288-306.

Lin Chih-Li , Chen Ta-Fu, Chiu Ming-Jang, Way Tzong-Der, Lin Jen-Kun. 2009. Epigallocatechin gallate (EGCG) suppresses amyloid-induced neurotoxicity through inhibiting c-Abl/FE65 nuclear translocation and GSK3 activation. Neurobiology of Aging. 30: 81-92.

Mandel S., Amit T., Bar-Am O., Youdim M.B. 2007. Iron dysregulation in Alzheimer's dis ease: multimodal brain permeable iron chelating drugs, possessing neuroprotectiveneurorescue and amyloid precursor protein-processing regulatory activities as therapeutic agents. Prog. Neurobiol., 82: $348-360$.

Mansuri M.L.,Parihar P.,Solanki I., Parihar M.S. (2014). Flavonoids in modulation of cell survival signalling pathways. Genes Nutr. 9 (3): 400.

Mattson M.P. and M.K. Meffert. 2006. Roles for NF-kB in nerve cell survival, plasticity, and disease. Cell Death and Differentiation. 13: 852-860.

Menard C., Bastianetto S., Quirion R. 2013. Neuroprotective effects of resveratrol and epigallocatechin gallate polyphenols are mediated by the activation of protein kinase $\mathrm{C}$ gamma. Frontiers in Cellular Neuroscience. 7: 281-8.

Misra Parimal, Owuor Edward D., Li Wenge, Yu Songtao, Qi Chao, Meyer Kirstin, Zhu Yi-Jun, Rao M. Sambasiva, Tony Kong A.-N. \& Reddy Janardan K. 2002. Phosphorylation of transcriptional coactivator peroxisome proliferatoractivated receptor (PPAR)-binding protein (PBP), Stimulation of transcriptional regulation by mitogenactivated protein kinase. Journal of Biological Chemistry. 277 (50): 4874548754.

Monsalve Y., Tosi G., Ruozi B., Belletti D., Vilella A., Zoli M., Vandelli M.A., Forni F., López B.L., Sierra L. 2015. PEG-g-chitosan nanoparticles functionalized with the monoclonal antibody OX26 for brain drug targeting. Nanomedicine. (10, 11): 1735-50.

Moskovitz J., Yim K.A., Choke P.B. 2002. Free radicals and disease. Arch Biochem Biopsy's. 397: 354-359.

Munin Aude and Florence Edwards-Lévy. 2011. Encapsulation of Natural Polyphenolic Compounds; a Review. Pharmaceutics. $(3,4): 793-829$.

Na H.K., Surh Y.J. 2006. Transcriptional regulation via cysteine thiol modification: a novel molecular strategy for chemoprevention and cytoprotection. Mol. Carcinog. (45, 6): 368-80.

Nicolas M. and B. A. Hassan. 2014. Amyloid precursor protein and neural development. Development. 141 (13): 2543-2548.

Nilsberth C., Westlind-Danielsson A., Eckman C.B., Condron M.M., Axelman K., Forsell C., Stenh C., Luthman J., Teplow D.B., Younkin S.G. 2001. The 'Arctic' APP mutation (E693G) causes Alzheimer's disease by enhanced Abeta protofibril formation. Nat. Neurosci. 4: 887-893.

Oddo S., Caccamo A., Cheng D., Jouleh B., Torp R., LaFerla F.M. 2007. Genetically augmenting tau levels does not modulate the onset or progression of Abeta pathology in transgenic mice. J. Neurochem. 102: 1053-1063.

Opazo C., Huang X., Cherny R. 2002. Metalloenzyme-like activityof Alzheimer's disease beta-amyloid. Cu-dependent catalytic conversion of dopamine, cholesterol, and biological reducing agents to neurotoxic H2O2. J. Biol. Chem. 277: 40302-40308.
Ou Jiang-Rong, Meng-Shan Tan, An-Mu Xie, Jin-Tai Yu, \& Lan Tan. 2014. Heat Shock Protein 90 in Alzheimer's Disease. Bio Med Research International Article ID 796869, 7 pages.

Pasello Michela, Michelacci Francesca, Isabella Scionti, Hattinger Claudia Maria, Zuntini Monia, Caccuri Anna Maria, Scotlandi Katia, Picci Piero, \& Serra Massimo. 2008. Overcoming Glutathione S-Transferase P1-Related Cisplatin Resistance in Osteosarcoma. Cancer Res. 68: 16.

Piao C. S., Kim D.-S., Ha K.-C., Kim H.-R., Chae H.-J., and Chae S.-W. 2011. The protective effect of epigallocatechin-3 gallate on ischemia/reperfusion injury in isolated rat hearts: an ex vivo approach. Korean Journal of Physiology and Pharmacology. 15 (5): 259-266.

Popa-Wagner Aurel, Smaranda Mitran, Senthilkumar Sivanesan, Edwin Chang \& Ana-Maria Buga. 2013. ROS and Brain Diseases: The Good, the Bad, and the Ugly. Oxidative Medicine and Cellular Longevity, Article ID 963520, 14 pages.

Kevin Punsky. 2014. Pathway that contributes to Alzheimer's disease revealed by research. Science News, https://www. sciencedaily.com/releases/2014/09/140919140738.htm.

Rao K.S.J., Rao R.V., Shanmugavelu P., Menon R.B. 1999. Trace elements in Alzheimer's disease brain: A new hypothesis. Alzheimers reports. 2: 241-246.

Romeo L., Intrieri M., D’Agata V., Mangano N.G., Oriani G., Ontario M.L., Scapagnini G. 2009. The major green tea polyphenol, (-)-epigallocatechin-3-gallate, induces heme oxygenase in rat neurons and acts as an effective neuroprotective agent against oxidative stress. J. Am. Coll. Nutr., (492S-499S).

Rossor M. N. 1993. Molecular pathology of Alzheimer's disease. Journal of Neurology, Neurosurgery \& Psychiatry. 56: 583-586.

Rui-Chun Lu, Meng-Shan Tan, Hao Wang, An-Mu Xie, JinTai Yu, \& Lan Tan. 2014. Heat Shock Protein 70 in Alzheimer's disease. Bio Med. Research International, Article ID 435203, 8 pages.

Scheuner D., Eckman C., Jensen M., Song X., Citron M., Suzuki N., Bird T.D., Hardy J., Hutton M., Kukull W., Larson E., Levy-Lahad E., Viitanen M., Peskind E., Poorkaj P., Schellenberg G., Tanzi R., Wasco W., Lannfelt L., Selkoe D., Younkin S. 1996. Secreted amyloid beta-protein similar to that in the senile plaques of Alzheimer's disease is increased in vivo by the presenilin 1 and 2 and APP mutations linked to familial Alzheimer's disease. Nat. Med. $(2,8): 864-70$

Schipper H.M. 2004. Redox neurology Visions of an emerging subspecialty. Ann. N.Y. Acad. Sci. 1012: 342-355.

Singh Neha Atulkumar, Mandal Abul Kalam Azad \& Kha Zaved Ahmed. 2016. Potential neuroprotective properties of epigallocatechin-3-gallate (EGCG). Nutrition Journal 15: 60 .

Sonee M., Sum T., Wang C., Mukherjee S.K. 2004. The soy isoflavone, genistein, protects human cortical neuronal cells from oxidative stress. Neurotoxicology. 25: 885-91.

Spencer Jeremy P.E. 2007. The interactions of flavonoids within neuronal signalling pathways. Genes Nutr. (2, 3): 257-273.

Spillantini M.G., Murrell J.R., Goedert M., Farlow M.R., Klug A., Ghetti B. 1998. Mutation in the tau gene in familial multiple system tauopathy with presenile dementia. Proc. Natl. Acad. Sci. USA. (95, 13): 7737-7741. 
Suzuki N., Cheung T., Cai X.D., Odaka A., Otvos L. Jr., Eckman C., Golde T.E., Younkin S.G. 1994. An increased percentage of long amyloid beta protein secreted by familial amyloid beta protein precursor (beta APP717) mutants. Science. (264, 5163): 1336-40.

Suzuki Y.J., Forman H.J., Sevanian A. 1997. Oxidant as stimulators of signal transduction. Free Radic. Biol. Med., 22: 269-285.

Swaran J.S. 2009. Structural, chemical and biological aspects of antioxidants for strategies against metal and metalloid exposure. Oxid Med. Cell. Longev. (2, 4): 191-206.

Takashima Akihiko, Noguchi Kaori, Michel Gilles, Mercken Marc, Hoshi Minako, Ishiguro Koichi, Imahori Kazutomo. 1996. Exposure of rat hippocampal neurons to amyloid $\beta$ peptide (25-35) induces the inactivation of phosphatidyl inositol-3 kinase and the activation of tau protein kinase $\mathrm{I} / \mathrm{glycogen}$ synthase kinase-3 $\beta$. Neuroscience Letters. (203, 1): 33-36.

Tarapore Rohinton S., Siddiqui Imtiaz A., \& Mukhtar Hasan. 2012. Modulation of Wnt/ $\beta$-catenin signaling pathway by bioactive food components. Carcinogenesis. 33 (3): 483-491.

Treiber C., Simons A., Strauss M., Hafner M., Cappai R., Bayer T.A., Multhaup G. 2004. Clioquinol mediates copper uptake and counteracts copper efflux activities of the amyloid precursor protein of Alzheimer's disease. J. Biol. Chem. 279: 51958-51964.

Turner, P. R., O'Connor, K., Tate, W. P., \& Abraham, W. C. 2003. Roles of amyloid protein and its fragments in regulating neural activity, plasticity and memory. Prog. Neurobiol. 70: 1-32.

Uttara Bayani, Ajay V. Singh, Paolo Zamboni, \& R.T Mahajan. 2009. Oxidative Stress and Neurodegenerative Diseases: A Review of Upstream and Downstream Antioxidant Therapeutic Options. Curr. Neuropharmacol. (7, 1): 65-74.
Vassar R., Bennett B.D., Babu-Khan S., Kahn S., Mendiaz E.A., Denis P., Teplow D.B., Ross S., Amarante P., Loeloff R., Luo Y., Fisher S., Fuller J., Edenson S., Lile J., Jarosinski M.A., Biere A.L., Curran E., Burgess T., Louis J.C, Collins F., Treanor J., Rogers G., Citron M. 1999. Betasecretase cleavage of Alzheimer's amyloid precursor protein by the transmembrane aspartic protease BACE. Science, (286, 5440): 735-41.

Velayutham P., Babu A., Liu D. 2008. Green tea catechins and cardiovascular health: An update. Curr. Med. Chem. 15: $1840-1850$

Wang C., Yu J.T., Miao D., Wu Z.C., Tan M.S., Tan L. (2014). Targeting the mTOR signaling network for Alzheimer's disease therapy. Mol. Neurobiol. 120-35.

Wan Wenbin, Xia Shijin, Kalionis Bill, Liu Lumei, \& Li Yaming. 2014. The Role of Wnt Signaling in the Development of Alzheimer's Disease: A Potential Therapeutic Target? Bio. Med. Research International, Article ID 301575, 9 pages.

Watt T.Nicole, Whitehouse Isobel J. and Nigel M. Hooper. 2011. Review Article. The Role of Zinc in Alzheimer's disease. Inter. J Alzheimers Dis., Article ID 971021, 10 pages.

Wu C. C., Hsu M. C., Hsieh C. W., Lin J. B., Lai P. H., Wung B. S. 2006. Upregulation of heme oxygenase-1 by Epigallocatechin-3-gallate via the phosphatidylinositol 3-kinase/Akt and ERK pathways. Life Sciences. (78, 25): 2889-2897.

Younkin, S. G. 1998. The role of A beta 42 in Alzheimer's disease. Journal of Physiology. 92 (3-4): 289-92.

Zhang H., Ma Q., Zhang,Y.-W., \& H. Xu. 2012. Proteolytic processing of Alzheimer's $\beta$-amyloid precursor protein. Journal of Neurochemistry. 120 (1): 9-21.

Zhao Yan \& Baolu Zha. 2013. Oxidative Stress and the Pathogenesis of Alzheimer's disease. Oxidative Medicine and Cellular Longevity, Article ID 316523, 10 pages

Zheng H. \& E. H. Koo. 2006. The amyloid precursor protein: beyond amyloid, Molecular Neurodegeneration. 1: 5. 